\title{
RELAÇÃO ENTRE DISLEXIA E PROBLEMAS DE APRENDIZAGEM
}

\author{
Adriana Bento Leme Alves ${ }^{1}$ \\ Elizete de Souza Piona ${ }^{2}$ \\ Priscila Elaine Joaquim ${ }^{3}$ \\ Cleidi Deckert ${ }^{4}$ \\ Janieli de Sousa Santos Suassuna ${ }^{5}$
}

RESUMO: mundo moderno onde vivemos atualmente exige que aprendamos uma série de habilidades, entre elas a leitura e escrita, que são importantes para que novas descobertas sejam alcançadas. Porém nem todos os indivíduos conseguem alcançar esse aprendizado na fase escolar, devido a fatores variados que impedem essa aprendizagem. Entre esses fatores existe um distúrbio chamado dislexia, que impede a natural aprendizagem da leitura e escrita, que se apresenta de forma mais clara nos primeiros anos do ensino fundamental. Logo a uma necessidade do educador conhecer os sintomas da dislexia para que seja possível viabilizar um plano de ação para minimizar os problemas de aprendizagem provocado pela dislexia, diante desse exposto esse trabalho de pesquisa se justifica. O presente trabalho tem o objetivo de pesquisar as dificuldades de aprendizagem de leitura e escrita provocadas pela dislexia, investigando quais as ações que podem ser tomadas pelos educadores em sala de aula para diagnosticar e tratar a dislexia.Para atingir os objetivos dessa pesquisa esse trabalho conta com uma revisão bibliográfica baseado em ideias de autores que já se debruçaram sobre o tema da dislexia. Nesse contexto o presente trabalho se desenvolve no sentido de definir o que é dislexia, apresentando as suas características e sintomas, assim como seu tratamento e o papel do educador em sala de aula frente a esse problema de aprendizagem.

Palavras-Chave: Dislexia. Aprendizagem. Leitura. Escrita.

ABSTRACT: The modern world in which we live today requires that we learn a range of skills, including reading and writing, that are important for new discoveries to be achieved. However, not all individuals are able to achieve this learning in the school stage, due to various factors that impede this learning. Among these factors there is a disorder called dyslexia, which prevents the natural learning of reading and writing, which presents itself more clearly in the first years of elementary school. Therefore, it is necessary for the educator to know the symptoms of dyslexia so that it is possible to make feasible a plan of action to minimize the learning problems caused by dyslexia. In view of this, this research work is justified. The present work has the objective of researching the difficulties of reading and writing learning caused by dyslexia, investigating what actions can be taken by classroom educators to

\footnotetext{
${ }^{I}$ Licenciada em Pedagogia pela Universidade Paulista-Polo Lins/SP.

${ }^{2}$ Licenciada em Pedagogia pela Universidade Paulista-Polo Lins/SP.

3 Licenciada em Pedagogia pela Universidade Paulista-Polo Lins/SP.

${ }^{4}$ Licenciada em Pedagogia pela Universidade Paulista-Polo Lins/SP.

5 Aluna do curso de pós-graduação lato sensu pela Faculdade Venda Nova do Imigrante-FAVENI. E-mail: janielisuassuna@gmail.com.
} 
diagnose andtreat dyslexia. To reach the objectives of this research, this work relies on a bibliographical review based on the ideas of authors who have already studied the topic of dyslexia. In this context the present work develops in the sense of defining what dyslexia is, presenting its characteristics and symptoms, as well as its treatment and the role of the educator in the classroom in front of this learning problem.

Keywords: Dyslexia. Learning. Reading. Writing.

\section{INTRODUÇÃO}

Durante o desenvolvimento da humanidade o homem foi inventandoferramentas e técnicas que foram aperfeiçoadas ao longo dos séculos, e entre elas oprocesso de leitura e escrita que proporcionou o acumulo de conhecimentos transformados em livros, textos, artigos, etc. Aliado a isso na atualidade a vida humana moderna exige que o indivíduo domine os métodos de leitura e escrita pois constantemente a uma necessidade de ler e produzir desde pequenas mensagens escritas até textos acadêmicos.

Nesse sentido a escola tem o objetivo inicial de promover a alfabetização, com o ensino da leitura e escrita nos primeiros três anos do ensino fundamental, porém a alfabetização é um processo longo. Para que o aluno tenha condições de progredir dentro da vida escolar, e também desenvolver capacidades de leitura e escrita para seu cotidiano fora da escola é preciso que ele desenvolva a habilidade de leitura e escrita.

Porém alguns alunos apresentam dificuldades de aprendizagem nessa fase escolar, que podem ter causas relacionadas a problemas psicológicos, distúrbios cognitivos, e outras doenças. Entre esses problemas que podem causar dificuldadesde aprendizagem da leitura e escrita existe a dislexia, que atrapalha o período de alfabetização, e geralmente é identificada nesses primeiros anos do ensino fundamental.

Segundo Barros (2007) dislexia é um distúrbio de aprendizagem onde o alunotem dificuldades de codificar as letras e palavras, conhecida também como "cegueira das palavras”. A Associação Brasileira de Dislexia (ABD) alerta que esse distúrbio afeta entre $5 \%$ e $15 \%$ das crianças brasileiras, e seu diagnóstico precoce é fundamental para que possam ser tomadas medidas para intervenção e tratamento da dislexia.

A uma dificuldade de diagnóstico inicial da dislexia, pois nem todos os professores conhecem os sintomas e características desse distúrbio, nesse sentido esse trabalho de pesquisa se justifica devido à proximidade que o educador tem em sala de aula com as dificuldades de aprendizagem dos alunos. O presente trabalho tem o objetivo de pesquisar 
as dificuldades de aprendizagem de leitura e escrita provocadas pela dislexia, investigando quais as ações que podem ser tomadas pelos educadores em sala de aula para diagnosticar e tratar a dislexia.

Após a definição do tema "Dificuldades na aprendizagem da leitura e escrita ea relação com a dislexia" foi realizada uma pesquisa bibliográfica em livros, artigos, textos e biblioteca virtual para a identificação de autores que já abordaram o tema. Feita a coleta de dados foi realizada uma seleção restando apenas obras bibliográficas que mais se aproximam do tema desse trabalho de pesquisa.

Para atingir os objetivos desse estudo, o trabalho conta com uma pesquisa bibliográfica que segundo Fonseca (2002 p. 32) "é feita a partir do levantamento de referências teóricas já analisadas, e publicadas por meios escritos e eletrônicos, como livros, artigos científicos, páginas de web sites”. Porém Gil (2010) lembra que a pesquisa bibliográfica não é apenas a transcrição de ideias de outros autores, massim uma análise aprofundada, e um confrontamento de teorias para o entendimento de um tema.

Esse é um tema relevante a educação, pois como visto anteriormente adislexia atinge uma porcentagem considerada dos alunos em sala de aula, além disso ela é confundida com outros problemas como preguiça do aluno e falta de interesse. Nesse sentido a uma necessidade de pesquisar, refletir e ampliar os conhecimentos sobre a dislexia, contribuindo para a formação docente e com novos saberes para a educação.

O presente trabalho de pesquisa se divide em três capítulos, no qual oprimeiro faz uma abordagem em torno das definições e concepções da dislexia, paraque seja possível compreender as suas características. O primeiro capítulo traz ainda uma abordagem em torno do diagnóstico da dislexia, e como o educador podeidentificar esse distúrbio, evitando assim conclusões erradas e atribuindo a falta de aprendizagem a outras causas.

O segundo capítulo faz uma abordagem em torno do papel do educadorfrente aos problemas de dislexia e como a sua formação reflexiva pode contribuir para a identificação e estratégias de aprendizagem diante desse problema de aprendizagem. Além disso o segundo capitulo traz ainda a atuação do psicopedagogo frente a dislexia, como esse profissional pode contribuir com a aprendizagem do educando com dislexia.

Para finalizar o último capitulo faz uma abordagem em torno de práticas pedagógicas em sala de aula, na qual o educador pode realizar atividades para desenvolver a leitura e 

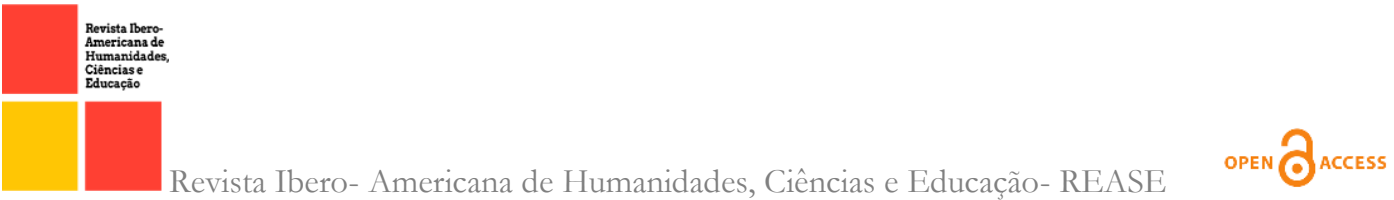

escrita do aluno com dislexia. Além disso, esse capitulo traz ainda o processo de avaliação do aluno com dislexia, e como o educador poderefletir sobre os níveis de aprendizagem do aluno com dislexia

\section{DISLEXIA}

Os problemas de aprendizagem de leitura e escrita sempre existiram naescola, porém no passado a origem dos problemas sempre eram relacionados a preguiça e falta de interesse dos alunos. A dislexia era praticamente desconhecida no meio educacional, logo os professores apresentavam outras causas para esse problema, e por muitas vezes com um diagnóstico errado o aluno acabava abandonando a escola.

Dentro desse contexto esse capitulo faz uma abordagem em torno das concepções da dislexia, para que seja possível compreender melhor esse distúrbio que atrapalha a aprendizagem da leitura e escrita. Esse capítulo apresenta ainda o diagnóstico e tratamento da dislexia para que o aluno consiga se desenvolver ao máximo sua capacidade de leitura e escrita.

\section{I Definição E História Da Dislexia}

Por muitos séculos o processo de ensino da leitura e escrita era feito apenasa um grupo restrito de pessoas, filhos dos nobres, o clero e escribas tinham acesso ao aprendizado dessas habilidades. Além disso nesse período quem tinha dificuldades de aprendizagem na escola era taxado como "burro", entre outras denominações que sugiram a falta de interesse do aluno pelo aprendizado da leitura e escrita.

Com a universalização do acesso à escola e a criação de métodos de alfabetização alguns estudiosos e professores passaram a perceber que havia alunos que apresentavam problemas de aprendizagem. Nesse sentido Barros (2007, p.I4I) cita que "a dislexia, descoberta em 1877 , por Kussmaul, que chamou de "cegueira às palavras, foi inicialmente estudada pela ciência médica”.

Rodrigues (2016) complementa que o oftalmologista inglês Pringle Morgam atribuiu a dislexia a uma falha no desenvolvimento da cortex cerebral, chamando de "cegueira verbal". O médico inglês chegou a essas conclusões sobre dislexia depois de estudar o caso de um menino de 14 anos que possuía uma inteligência normal e boa saúde, porém apresentava dificuldades de aprender a leitura e escrita. 
Barros (2007, p. I4I) cita que:

Em 190o, Hinschelwood, outro oftalmologista inglês, verificou fenômeno idêntico. Entre os casos que ele observou, há o de um menino de onze anos que, com excelente memória e sabendo de cor todas as lições, tão inteligente quanto seus irmãos, com quatro anose meio de escola não tinha conseguido aprender a ler.

Rodrigues (2016) afirma que em I917 Hinschelwood passou a chamar essa cegueira das palavras de "dislexia", sendo então estudada por médicos, psicólogos eeducadores. Ao longo das décadas seguintes outros médicos passaram a estudar a dislexia e houve a formulação de diferentes teorias em relação as causas e formas de tratamento desse distúrbio, porém o mesmo autor cita que a dislexia foi estudada de maneira separada no campo médico e na sala de aula, fato que por vezes dificultava um diagnóstico completo.

Como é possível observar a dislexia é um distúrbio que afeta pessoas com boa saúde e inteligência normal, com sua descoberta relativamente recente remetendo a pouco mais de um século atrás. Com estudos distintos e controversos,e até hoje a dislexia ainda não é aceita por professores, que apontam outros fatores que levam a dificuldade de aprendizagem em sala de aula.

Para efeitos de definição Rodrigues (2016, p. 87) assevera que:

A dislexia é um transtorno específico de aprendizagem, de origem neurológica. Acomete pessoas de todas as origens e nível intelectual e caracteriza-se por dificuldade na precisão (e/ou fluência) no reconhecimento de palavras e baixa capacidade de decodificação e de soletração. Essas dificuldades são resultado de déficit no processamento fonológico, que normalmente está abaixo do esperado em relação a outras habilidades cognitivas. Problemas na compreensão e reduzida experiência de leitura normalmente são as consequências secundárias desse transtorno.

Nesse sentido Barros (2007) lembra que a dislexia precisa ser identificada e tratada, pois pode ser provocadora de outros problemas na vida do aluno dentro da escola, como também na sua vida cotidiana. Portanto a uma necessidade que educadores tenham conhecimento sobre esse distúrbio na aprendizagem, e saibam identificar e encaminhar o aluno para tratamentos com psicólogos, assim como desenvolvam estratégias dentro da sala de aula para minimizar os efeitos desse distúrbio de aprendizagem.

Ladeira (2009, p. 3) complementa dizendo que "a dislexia, enquanto deficiência da linguagem no campo neurológico, traz dificuldade na leitura, na pronuncia e nas habilidades de soletração. $O$ distúrbio constui-se em muitas alterações na linguagem, principalmente na 
leitura e escrita".

Além disso, é sabido que a fase inicial de alfabetização é o momento onde acontece os maiores índices de diagnóstico da dislexia, pois é na aprendizagem da leitura e escrita que os problemas de aprendizagem aparecessem econsequentemente a busca de respostas para essa dificuldade em aprender. Portanto o educador precisa conhecer os sintomas da dislexia, identificando precocemente esse distúrbio de aprendizagem e fazer o encaminhamento e tratamento dos educandos que apresentam esse tipo de dificuldade em sala de aula.

\subsection{Diagnóstico Da Dislexia}

Como citado anteriormente frente ao problema de aprendizagem da leitura e escrita do aluno a uma necessidade de identificação de quais fatores ou distúrbios podem estar ligados a esse fato. Logo é preciso conhecer quais são os sintomas e características do aluno com dislexia para que seja possível a identificação e montagem de estratégias para a correção do problema.

Nesse sentido Barros (2007, p. 142) cita algumas características dos alunos com 1435 dislexia:

a) inverter a ordem das letras. Por exemplo: rop ou pro, em vez de por;

b) trocar letras, pois confunde ao ouvir ta e da, ou fa e va etc.;

C) nunca saber, com segurança, de que lado fica a parte redonda dasletras $d$ e b, ou p e q. (Fica do lado de cá ou de lá?) (Porque ser mal lateralizado, o aluno sempre hesita em dizer parte de cima da de baixo;

d) não distinguir o $\mathrm{n}$ do $\mathrm{u}$ por não saber, ao certo, distinguir $\mathrm{n}$ partede cima da de baixo;

e) confundir o m e o $\mathrm{n}$ por serem parecidos etc. Ainda, algumas crianças apresentam escrita invertida que é comumente chamada "escrita ao espelho": $\mathrm{E}=3$.

Rodrigues (2016, p. 88) aponta ainda outros sintomas como "dificuldade para compreender o sentido do que é lido. Pode realizar leitura com precisão, porém não compreende a sequência, as relações, as inferências ou os sentidos mais profundos do que é lido”. O mesmo autor complementa que o aluno apresenta graus diferentes nessas dificuldades citadas, porém ao final não consegue aprender a ler e escrever de maneira compatível com sua fase escolar.

Além desses sintomas de dislexia citados a cima, é importante destacar que com o 

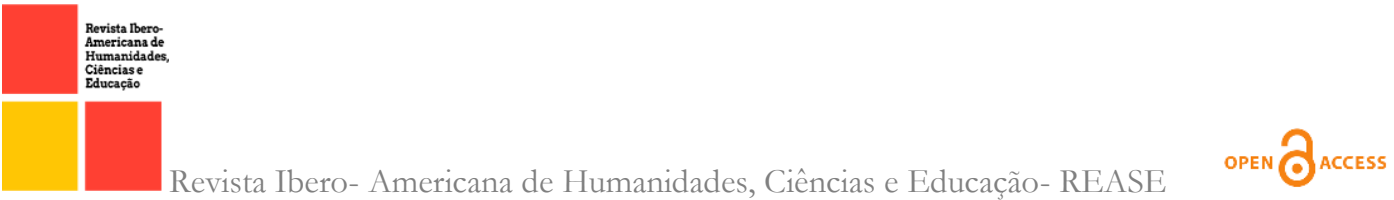

passar do tempo dentro da escola e o fracasso na aprendizagem o aluno passa apresentar outras características como consequência da dislexia. Barros (2007, p. 42) cita que "os erros na leitura e escrita parecem resultar não apenas da própria dificuldade em lidar com símbolos, mas também de dificuldades emocionais que vão se acumulando pelos fracassos repetidos. A ansiedade intervém, em grau variável, nesses distúrbios”.

Ladeira (2009) aponta que o diagnóstico da dislexia deve ser realizado por profissionais especializados como médicos e psicólogos, que realização testes e processos de exclusão de sintomas. Porém muitas vezes esse aluno apenas chega até os profissionais especializados pelo encaminhamento do professor ou família, portanto é necessário que os educadores tenham atenção com o aluno para que frente a um problema de aprendizagem e possível suspeita de dislexia conduzam para avaliação com profissionais especializados.

Porém o diagnóstico é uma tarefa desafiadora, pois a dislexia ainda é pouco conhecida no meio escolar por parte dos professores, que ainda rejeitam esse distúrbio. Além disso os sintomas da dislexia se confundem com outros distúrbios deaprendizagem, além da própria dislexia ter subdivisões com sintomas e causas distintas entre si.

\subsubsection{Tipos De Dislexia}

A dislexia pode ser apontada através de testes feitos por equipes multiprofissionais que contam com médicos, fonoaudiólogos, neurologistas, psicólogos e pedagogos. Na busca dos tipos de dislexia na bibliografia não foi encontrada uma exatidão de termos, pois se observou que dependendo de cada profissional a termologia pode ser alterada.

Teixeira (2015) classifica dislexia da seguinte forma:

- Dislexia disfonética: É a dificuldade de perceber os fonemas através da audição, além disso apresenta dificuldades temporais, trocando os dias da semana ou confunde o ontem com o amanhã. Apresenta maior dificuldade na leitura de palavras que não apresentam nenhum significado, e faz alterações na ordem de palavras e letras, e fica evidenciado a dificuldade com a escrita.

Dislexia Diseidética: Se caracteriza pela dificuldade na percepção visual das palavras, conseguindo ler as silabas, porém não tem dificuldades na formaçãoda palavra. Apresenta maior dificuldade da leitura do que na escrita.

- Dislexia visual: Apresenta dificuldades na visão e coordenação daquilo que esteja 
olhando, então o indivíduo enxerga, porém, tem dificuldades de processar as informações.

- Dislexia auditiva: Se caracteriza pela a dificuldade de perceber os sons, escuta, porém tem dificuldades de processar as informações.

- Dislexia Mista: É caracterizada pelos indivíduos que apresentam mais de umtipo de dislexia citados acima.

Prestes (2016) complementa que a classificação da dislexia e a nomeação depende do profissional que faz a avaliação do aluno, além disso existe uma discordância entre alguns médicos e pesquisadores. Pois alguns desses profissionais delegam maior importância há um tipo de dislexia especificadamente, como é o caso dos defensores da dislexia fonética.

Mojen (2016) lembra que a dislexia ainda na atualidade é tratada de forma geral, e muitas vezes a criança que tem dificuldades em ler e escrever é apenas diagnosticada com dislexia. Mas não existe uma divisão entre os tipos da dislexia e com isso o tratamento pode ser não feito de maneira correta, não alcançando os objetivos de melhoria.

Para Teixeira (2015) a dislexia é um distúrbio complexo, que não fica centralizado em sintomas gerais, mas sim existe uma diferença entre sujeitos disléxicos. Conhecer e 1437 compreender essas diferenças é um fator central para a elaboração de soluções e um tratamento mais adequada a melhoria dos sintomas doindivíduo.

Mojen (2016, p.2) cita que:

A constatação de que nem todos os disléxicos apresentam alteração no processamento auditivo pode significar que existem tipos diferentes de dislexia, sendo um deles associado à alteração noprocessamento auditivo, ou apenas que os déficits podem ter sido superados.

Como é possível observar existem uma distinção entre os tipos de dislexia e que seu diagnóstico deve ser preciso, identificar quais são as características do disléxico é um fator determinante. Não é possível apenas tratar a dislexia de maneira ampla, mas sim conhecer todos os fatores que influenciam na aprendizagem do aluno.

Segundo Teixeira (2015) o diagnóstico e a tipagem da dislexia devem ser feitopor profissionais que tenham competência para afirmar com certeza qual é o tipo de dislexia do sujeito. Pois somente o atestado de dislexia é uma forma geral deapontar o problema e que não tem eficácia no tratamento.

Portanto o diagnóstico preciso em relação a dislexia e seu tipo é o primeiro passo para que os professores consigam trabalham com iniciativas que atendam a necessidade dos alunos. O tratamento e intervenção depende exclusivamente no acerto do diagnóstico sobre qual é o 
tipo de dislexia que o aluno possui.

\subsection{Tratamento da Dislexia}

Após o diagnóstico positivo para dislexia a uma necessidade de intervenção de profissionais preparados para o tratamento desse transtorno de aprendizagem. Massi (2006) destaca que quanto mais cedo seja descoberta a dislexia, antes é possível entender esse problema evitando o aparecimento de outras dificuldades como uma auto estima baixa da criança e rejeição a escola e a aprendizagem.

Então como é possível compreender o primeiro passo é diagnosticar a dislexia, entendendo de onde vem as dificuldades de aprendizagem da criança, paraque isso se torne um elemento positivo na busca de processos de intervenção. Ladeira (2009, p. 4) destaca que "ao trabalhar em conjunto, educadores, pais/cuidadores e especialistas podem auxiliar a criança a superar esta dificuldade".

A identificação e conhecimento sobre a dislexia ajuda a criança, pais e professores a ter outra visão sobre esse transtorno, partindo em direção de estratégias para minimizar os problemas de aprendizagem provocados por esse transtorno. Nesse sentido Lima (2012, p. io) lembra que:

A criança disléxica, que sente necessidades de aprendizagem é umacriança normal que necessita aprender de forma diferenciada. Apesar da dificuldade que o disléxico sente na apropriação da linguagem fala da e escrita, a dislexia não é uma doença, e não existe medicamento para o distúrbio existe sim, tratamento para disléxicos.

Massi (2006) complementa que não há cura para a dislexia, porém com um diagnóstico correto, e intervenção precoce de profissionais preparados para trabalhar com esse transtorno é possível que o indivíduo tenha uma vida normal. "A criança que possui o distúrbio precisa ter um atendimento prioritário, que seja conduzido por um especialista que oriente o professor e aluno para que haja um suporte pedagógico apropriado" (LIMA, 20I2, p. io).

Segundo Massi (2006) existem diferentes caminhos para o tratamento da dislexia, isso se deve muito a complexidade que é envolvida no processo de aquisição da habilidade da leitura e escrita. Diante disso a uma necessidade de entender os processos de aprendizagem da leitura e escrita, e a adaptações e caminhos que ficam próximos ao desenvolvimento natural dessa habilidade. 
Muszkat (2017, I19) aponta que:

Tal trabalho tem como objetivo oferecer oportunidades para a escrita e leitura espontâneas; explorar constantemente as diversas funções da escrita (não apenas produção textual, mas também cartas e bilhetes); e explicitar as diferenças entre língua falada e língua escrita. É importante que a criança tenha adequada consciência de que a fala e a escrita são formas diferentes de expressão de linguagem. Nas crianças com dislexia, a intervenção mais apropriadaé a que se baseia na estimulação da conversão grafema-fonema (não lexial) com intervenção direta de habilidades de leitura, associada a atividades relacionadas ao processamento fonológico da linguagem.

Assim é possível entender que a leitura e escrita devem ser constantemente estimuladas na criança com dislexia, para que essa desenvolva habilidades próprias,crie estratégias para a aprendizagem. Dentro desse contexto Massi (2006) lembra que o tratamento da dislexia não segue uma fórmula pronta, mas sim é preciso contar com a percepção do psicólogo e do educador para fazer adaptações de conteúdos e estratégias no sentido de aproximar a criança disléxica daquela ação que apresenta melhores resultados.

Muszkat (2017, p. 120) assevera que:

A estimulação por meio de canto, conversa, brincadeiras e leitura propicia a aquisição de habilidades que favorecem o desenvolvimento da motivação para tais habilidades, o que se chamade intenção comunicativa (pela fala serão conseguidos objetos de interesse da criança).

Logo, fica claro que o tratamento da dislexia depende em um primeiro momento do diagnóstico desse distúrbio que deve ser feito por profissionais preparados e especializados. Para somente então montar estratégias para a estimulação do desenvolvimento da leitura e escrita pelo disléxico, sempre acompanhando sua evolução e dificuldades afim de aproximar as estratégias positivas ao caminho da aprendizagem.

\section{DISLEXIA NO CONTEXTO EDUCACIONAL}

Como visto anteriormente a dislexia é um problema que impede o aluno de aprender a ler e escrever, e atrapalha a alfabetização, pois através da leitura e escrita é possível adquirir boa parte dos conhecimentos em sala de aula. No entanto esse transtorno de aprendizagem requer uma atuação conjunta entre escola e família, educador e psicopedagogo, onde cada um deles contribui de sua maneira, mas ao final é possível auxiliar o educando com dislexia.

Esse capitulo faz uma abordagem em torno da atuação do educador e da família em 
relação ao aluno com dislexia, e como a escola juntamente com a família podem organizar ações em relação a dislexia. Além disso, a atuação do psicopedagogo é importante para elaborar estratégias com o objetivo de desenvolver a aprendizagem do aluno com dislexia.

\subsection{O Papel Do Educador}

Nos últimos anos o papel do professor em sala de aula tem sofrido modificações significativas na maneira de ensinar, a tecnologia e a globalização de informações e conhecimentos deixaram os saberes ao alcance de todos os indivíduos. Em sala de aula o aluno chega trazendo uma bagagem de conhecimentos que adquiriu através da televisão e internet além de ouras mídias que estão ao alcance de todos, e proporcionam a aprendizagem de inúmeros conhecimentos que décadas atrás os educandos tinham contato apenas na escola.

Esse novo contexto exige que os educadores direcionem seus olhares paraa aprendizagem do aluno, deixando para trás aquele foco que estava voltado apenas para o processo de ensino. Com isso o educador passa a valorizar aaprendizagem do aluno, e quando isso não acontece a uma necessidade de buscar respostas para o fracasso escolar.

Lima (2012, p.I4) assevera que "há situações importantes em que o professor deve renovar sua prática pedagógica, principalmente nas situações onde adificuldade de aprender e entender persiste". Diante desse exposto o educador necessita estar atento aos distúrbios que provocam dificuldades de aprendizagem como é o caso da dislexia, identificando e atuando junto com psicólogos e a família para proporcionar melhoria na aprendizagem da leitura e escrita do aluno disléxico.

Segundo Medeiros (2012) há uma necessidade de o professor ter umaformação completa em relação aos conhecimentos sobre transtornos de aprendizagens. Não precisa ser uma especialista no assunto, mas necessita saber identificar quais são as possíveis causas dos problemas de aprendizagem do aluno em sala de aula para que aconteça um encaminhamento para outros profissionais que possam aprofundar os estudos $e$ as montagens de estratégias para corrigir o problema.

Caso contrário, Lima (2012, p. 14) cita que:

Com a falta de conhecimento existe a grande probabilidade de o professor culpar o aluno pelo insucesso assim, o professor não pesquisa e nem procura estudar e utilizar outros métodos para que a criança aprenda e entenda o conteúdo da melhor forma entendendoe respeitando a sua individualidade. 
Assim o principal papel do educador em sala de aula está ligado ao conhecimento do que é dislexia, como identificar esse distúrbio, e quais são as estratégias para minimizar seus efeitos na aprendizagem do aluno. Evitando uma série de consequências futuras com o insucesso escolar, abandono e desmotivação pela a escola, e dificuldades de novas aprendizagem a medida que avança dentro da vida escola pois boa parte do conhecimento é adquirido através da leitura.

Ladeira (2009, p. 3) assevera que:

Frente à sintomatologia da dislexia, entende-se que o papel do educador é de extrema importância na vida desses educandos, haja vista ter a sensibilidade de perceber a necessidade de seu educando por meio dos sinais que apresentam no decorrer de sua vida estudantil. Ao observar o educando e desconfiar de algum problema deve-se investigar e encaminhá-lo para um diagnóstico correto. Em seguida, deve-se iniciar um tratamento e realizar um trabalho específico para com esta criança em parceria com os pais, a comunidade educativa e os especialistas que fazem parte da equipe multidisciplinar.

Portanto o educador pela sua experiência com alfabetização pode ser a primeira pessoa a identificar o aluno com dislexia, pois frente a muitos sintomas que esse distúrbio apresenta a dificuldade na leitura e escrita é o mais evidente. Logo o educador pode auxiliar na identificação do problema e realizar o encaminhamento necessário para que estratégias de tratamento sejam montadas afim de auxiliar naaprendizagem e escrita.

\section{I A importância da participação da família}

No momento atual a família se encontra distante da escola, por diferentes motivos. Um desses motivos é a falta de tempo, a vida moderna nos obriga a trabalhar cada dia por mais horas, com isso a família possuí menos tempo para fazerum acompanhamento dos alunos na escola.

Com a vida moderna observa-se que a família tem trabalhado muito para manter seu padrão de vida, com isso acabam não acompanhando seus filhos na escola. Muitos têm simplesmente na escola um local onde seus filhos podem ficar enquanto eles trabalham, e todos sabem que a educação é um dever de todosfamília e escola em parceria, então essas duas instituições não podem ficar afastadas como estão nesse momento.

Mário Sérgio Cortella em entrevista ao Jornal Estadão faz uma citação pertinente ao tema, dizendo que: 
A família precisa retomar o seu papel, porque ter filho dá trabalho. Ouserá que as pessoas não sabiam? Existe tempo, aplicação, reordenamento, partilha das tarefas. A escola não tem como dar conta de tudo o que dela hoje se requisita. Quando há um linchamento, querem que a escola fale sobre linchamento. O mesmo ocorre com briga em estádios, corrupção, etc. E nem adianta o pai oua mãe dizer: "A gente paga, a gente quer o serviço". É preciso uma parceria entre a escola e as famílias. Uma ideia é manter, como algumas instituições fazem, uma escola de pais, com reuniões periódicas para ajudar as famílias na reflexão. (CORTELLA 2014).

Então levando em consideração essa citação, e os problemas analisados o tema se justifica, e a família precisa ser motivada a retornar o contato com a escola. E esse contato deve ser criado pela escola, usando meios disponíveis atualmente, como a tecnologias digitais entre outros possíveis.

A família e escola são duas instituições homogêneas, onde cada uma delastem sua obrigação dentro do processo de ensino aprendizagem. Esse é um processo que está citado pela UNESCO, no documento "Interação escola-família: subsídios para práticas escolares”,

Podemos dizer que a relação entre escola e família está presente, de forma compulsória, desde o momento em que a criança é matriculada no estabelecimento de ensino. De maneira direta ou indireta, essa relação continua viva e atuante na intimidade da sala de aula. Assim, sempre que a escola se perguntar o que fazer para apoiar os professores na relação com os alunos, provavelmente surgirá a necessidade de alguma interação com as famílias. Nesta corrente, cabe aos sistemas de ensino o estabelecimento de programas e políticas que ajudem as escolas a interagir com as famílias, apoiando assim o processo desenvolvido pelos professores junto aos alunos. (UNESCO 2009 p I4).

Como podemos observar na citação acima, escola e família formam uma aliança para ajudar professores e alunos, essa união é benéfica para todo o sistema de ensino. Além disso quando os problemas são resolvidos juntos, se cria um elo positivo entre escola-família, “a escola nunca educará sozinha, de modo que a responsabilidade educacional da família jamais cessará. Uma vez escolhida a escola, a relação com ela apenas começa. É preciso o diálogo entre escola, pais e filhos”. (REIS, 2007, p. 6).

Além disso a escola também deve levar em consideração os ensinamentos que a família exerce sobre os alunos, essa importância é citada nos Parâmetros Curriculares Nacionais de 1997, onde cita que:

Os alunos não contam exclusivamente com o contexto escolar para a construção de conhecimento sobre conteúdos consideradosescolares. A mídia, a família, a igreja, os amigos, são também fontes de influência 
educativa que incidem sobre o processo de construção de significado desses conteúdo. Essas influências sociais normalmente somam-se ao processo de aprendizagem escolar, contribuindo para consolidálo; por isso é importante que a escola as considere e as integre ao trabalho. (BRASIL, 1997, p.23).

Portanto não fica dúvidas quanto a importância da participação da família na escola, porém não é isso que está acontecendo. Romanelli (2005, p.7) cita que "uma das transformações mais significativas na vida doméstica e que redunda em mudanças na dinâmica familiar é a crescente participação do sexo feminino na força de trabalho, em consequência das dificuldades enfrentadas pelas famílias”.

Como cita o autor, essas mudanças familiares acabaram causando mudanças no contato família-escola, as mães que antes eram mais participativas na educação, hoje estão tendo que trabalhar fora. Então os filhos ficam desassistidos quanto ao acompanhamento escolar, e se perde muito com esse fato, onde a instituição famíliadeixa de exercer seu papel na formação conjunta do aluno.

Segundo Carneiro (2011, p. 52) "os pais têm uma grande importância e é objecto de atenção redobrada, uma vez que a falta de bem-estar no seio da mesma, motivada por complicações ou dificuldades, pode ser a causa dos problemas dos seus descendentes". Salvari (2006) complementa que a família deve acompanhar e apoiar o aluno, pois é nessa instituição que o aluno com dislexia deve encontra o apoio emocional e um acompanhamento a outros profissionais como é o caso do psicopedagogo.

Logo se observa que a participação familiar no atendimento de alunos com dislexia é uma necessidade para conseguir vencer esse problema de aprendizagem e realizar o desenvolvimento e aprendizagem do educando. Assim, cabe a escola mover ações para alertar a família desse problema e como deve ser feito o acompanhamento do aluno.

Carneiro (2011, p. 52) assevera que:

No momento do diagnóstico, alguns pais apesar de manifestarem sentimentos de medo e de insegurança podem ser bem sucedidas na adaptação, mostrando-se realistas, e com capacidade para ultrapassar a situação e assim aprender a viver a sua nova realidade.Em contrapartida, os pais que ao início estão menos preparados para aceitar esta realidade, investem, adaptam-se e evoluem de forma tãoevidente, que a situação inicialmente complicada não produz efeitos negativos, pelo contrário tornase numa experiência enriquecedora. Por estes motivos, a tensão provocada pela existência de um filho com dislexia pode durar os vários períodos ao longo do seu percurso escolar.

A escola através dos professores e orientador educacional deve manter umacurta 
relação com a família, mantendo informado e acompanhando todos os procedimentos para a melhoria do problema de dislexia. Encaminhando o aluno com dislexia para o psicopedagogo e psicólogo, e estando por dentro de todas as informações que cercam esse transtorno que atrapalha a aprendizagem do educando em relação a leitura e escrita.

Portanto a atuação da escola e família é decisiva no tratamento da dislexia, essas duas instituições devem uma proximidade para que seja possível superar os problemas da dislexia. Além disso, o acompanhamento tem o objetvo de valorização do educando, fator que favorece o processo de melhoramento da dislexia, eencontra diferentes maneiras de desenvolver habilidades no educando.

\section{A ATUAÇÃO DOCENTE EM SALA DE AULA E A DISLEXIA}

A atuação docente vem se modificando nos últimos anos, o professor não é mais o centro do processo educacional, esse fato não diminuí a importância do educador em sala de aula. Apenas aponta para uma mudança nas metodologias de ensino, esse fator é importante pois oportuniza a possibilidade de desenvolvimento do aluno com problemas de aprendizagem.

Esse capítulo faz uma abordagem em relação a importância do professor mediador em sala de aula para o desenvolvimento e aprendizagem do aluno com dislexia. Além disso, esse capítulo aborda ainda a avaliação educacional como ferramenta pedagógica para o desenvolvimento do aluno com dislexia e como ela deve ser usadas em sala de aula.

\section{I O professor mediador e dislexia}

A atuação do professor em sala de aula por muitos anos foi baseada em metodologias de ensino que tinham a transmissão de conhecimentos e conteúdos para os alunos que ocupavam uma postura passiva em sala de aula. As aulas em sua maioria aconteciam pela exposição de conteúdos pelo professor, que era o centro do processo de ensino, e não existia uma preocupação com o aluno em relação a problemas de aprendizagem, a sua evolução era feita através de avaliações que aprovavam ou reprovavam o aluno a cada ano letivo.

Segundo Gebran (2009) nos últimos anos algumas transformações vêm acontecendo na sociedade, as novas tecnologias modificaram instantaneamente a vida das pessoas, profissões foram criadas enquanto outras deixaram de existir, maneira de ensinar também se transformou. Com a internet o conhecimento está ao alcance de todos, o professor não é 
mais o único detentor do saber, com acesso a smartphones, tabletes e computadores o aluno rapidamente consegue realizar uma busca na rede e encontra qualquer assunto.

A partir dessas mudanças e novos olhares de teóricos e estudiosos da educação a atuação docente em sala de aula passa a exigir uma nova postura do educador frente o aluno. Há uma necessidade de um olhar atento para a demanda educacional em sala de aula, pesquisar e refletir sobre as características de cada aluno e elaborar estratégias que possam desenvolver habilidades no educando, contribuindo assim para a formação pessoal, profissional e social do aluno, preparando para a vida em sociedade. (RAMOS, 2012).

Dentro desse contexto que se afirma a figura do professor mediador deaprendizagem, que atua como um guia do aluno em busca do conhecimento, em umcampo onde os saberes são construídos pelo educando. Nesse sentido, o educador deixa para trás a atuação baseada em aulas expositivas e busca uma metodologia que motive $o$ aluno a aprender, transformando sua presença em sala de aula,baseada em uma postura ativa diante dos conteúdos que fazem parte das bases curriculares.

Logo se observa a necessidade de um professor que seja um mediador de 1445 aprendizagens, ainda mais dentro da educação que as crianças estão frente ainúmeras descobertas e interações. O educador necessita articular todos essesfatores para que se consiga atingir o desenvolvimento de experiencias positivas para formação do educando.

Isso fica evidenciado na citação a seguir:

A interação durante o brincar caracteriza o cotidiano da infância, trazendo consigo muitas aprendizagens e potenciais para o desenvolvimento integral das crianças. Ao observar as interações e abrincadeira entre as crianças e delas com os adultos, é possível identificar, por exemplo, a expressão dos afetos, a mediação das frustrações, a resolução de conflitos e a regulação das emoções. (BRASIL, 2017, p.35).

Diante dessa necessidade o educador deve buscar envolver os educandos em atividades lúdicas que utilizam as novas tecnologias em sala de aula, ampliando seu campo de atuação. Oliveira (2009) lembra apenas que muitas vezes o lúdiconão é considerado uma ferramenta de aprendizagem, principalmente por pessoas fora da escola, nesse sentido a uma necessidade que se busque efetivar essa abordagem com um planejamento e objetivos claros.

Essa mediação do educador é determinante para o sucesso ou fracasso da utilização da ludicidade em sala de aula, isso fica claro nas palavras de Navarro (2012, p. 634): 
O valor que determinadas brincadeiras terão para as crianças na escola dependerá muito de como elas serão encaradas, nesse contexto, pelos adultos que o frequentam. As formas de mediação realizadas pelo professor, a organização dos espaços e tempos da escola e dos materiais que se encontram ao alcance das criançasnos momentos de brincadeiras, são atitudes que podem fazer adiferença no brincar da escola.

Como é possível observar a mediação do educador é um fator determinante para a aprendizagem da criança, as brincadeiras devem ser projetadas para que desenvolvem competências nos educandos. Nesse sentido segundo Brasil (2017, p.37) "impõe a necessidade de imprimir intencionalidade educativa às práticas pedagógicas na Educação Infantil, tanto na creche quanto na pré-escola”.

Essa intencionalidade educativa passa pela presença de um professor mediador de aprendizagem, trabalhar com o lúdico aliado as novas tecnologiasexige que o professor mergulhe no universo infantil. "É essencial que se entenda o brincar como atividade dinâmica. Em cada contexto as crianças brincam de formas diferentes, assim como, para diferentes gerações, algumas formas de brincar também mudam” (NAVARRO, 2012, p. 635).

Já em relação a dislexia Alves (2014, p.9) assevera que:

Entre os diversos desafios a serem vencidos, a falta de informaçõese a pouca flexibilidade de ações metodológicas, são uma enorme dificuldade para se fazer qualquer mudança ou adaptação que não esteja prevista ou programada no planejamento do educador e no método da escola.

Como visto os métodos tradicionais de ensino não deixam espaço para uma mediação entre educador e educando, sendo nessa mediação que o educador se aproxima do aluno e compreende melhor suas necessidades. Nesse sentido a uma necessidade de um professor mediador no processo de ensino aprendizagem, que contribua com o aluno com dislexia.

\subsection{Prática Docente em sala de aula}

Após a identificação da dislexia no aluno e a realização de encaminhamentos o educador deve pensar na elaboração de estratégias para desenvolver as habilidades de leitura e escrita no educando. No entanto essa não é uma tarefa fácil,é preciso reflexão e pesquisa por parte docente, além disso há uma necessidade de ir em busca de metodologias que apresentem sucesso na alfabetização do educando com dislexia. (ALVES, 2014).

Segundo Navarro (2012) o aluno com dislexia tem um tempo próprio para realizar suas atividades, e não pode ser comparado com os demais alunos, énecessário que o professor 
compreenda esse fator diferencial. O aluno com dislexia não consegue acompanhar o ritmo dos demais alunos, e isso não deve ser interpretado de maneira errada.

Almeida (2009, p.II) assevera que:

Pais e professores devem trabalhar em conjunto para que o aluno valorize o que ele mesmo faz, dessa forma aumentará a sua motivação e restaurará a sua autoconfiança. Não esquecendo que esse aluno será mais lento que os demais e o educador precisa ser paciente. Em relação as avaliações o disléxico precisa de mais tempo para realizar as provas, as quais aconselham-se que sejam orais.

Assim o educador necessita observar essas características no aluno, pois caso não respeite esse tempo pode levar o aluno a uma frustração, e consequentemente não consegue obter sucesso dentro do processo de ensino aprendizagem. Então o professor possui "um papel fundamental no trabalho com crianças disléxicas. $O$ sucesso na aprendizagem dependerá também do cuidado em relação à leitura e das estratégias de ensino utilizadas" (RODRIGUES, 2018, p.9).

Logo o educador deve buscar estratégias que atendam a demandaeducacional do aluno com dislexia, para que ele consiga desenvolver a leitura e escrita mesmo que isso acontece de maneira lenta. Pois, o educador não pode apressar o processo da aprendizagem do aluno com dislexia.

Almeida (2009, p. II) complementa que:

Dentro da sala de aula o educador necessita da utilização de estratégias diferenciadas, como a utilização de recursos estimulantes, para que ele possa ver, sentir, ouvir e manusear como jogos, cartazes, cd, etc.

Nesse sentido o educador deve criar atividades que estimulem a concentração do aluno com dislexia, pois sua aprendizagem depende da sua dedicação. Navarro (2012) lembra que o aluno com dislexia necessita de atividades que mantenham o aluno concentrado, e ao mesmo tempo tragam algum tipo de prazer e satisfação, pois é isso que leva qualquer individuo a aprender algumconceito.

Rodrigues (2018, p.3) assevera que:

Os disléxicos, ao lerem, têm que se concentrar inteiramente na decodificação de palavras em vez de pensar na compreensão. Comoreflexo dessa falta de fluência sua compreensão é comprometida, por isso os disléxicos recorrem frequentemente ao contexto e a suabagagem de conhecimentos para expressar a sua compreensão.

Logo cabe ao educador compreender essas características particulares do aluno com 
dislexia, apresentando atividades que possam estimular essa concentração e compreensão. Alves (2014) lembra que o educador deve evitar as atividades prontas e usadas como padrão para todos os alunos, pois cada aluno é único e se motiva de acordo com seus gostos particulares.

Almeida (2009, p. 9) complementa que:

O professor deverá tratar o aluno com naturalidade, usar sempreuma linguagem clara e objetiva, falar olhando diretamente para ele, trazer o aluno próximo do educador, verificar discretamente se ele está entendendo a sua exposição para não colocá-lo em evidencia, observe se ele está fazendo as anotações da lousa antes de apagá- la.

Portanto como é possível observar o educador deve ter um olhar específico para o aluno com dislexia, compreendendo o tempo de aprendizagem e as características distintas dos demais educandos. Para que esse processo de alfabetização obtenha resultados positivos, e mesmo na dificuldade se consiga atingir o máximo de desenvolvimento das habilidades de leitura e escrita em todosos alunos.

Segundo Prestes (2016) o professor deve conhecer e pesquisar estratégias e 1448 metodologias de ensino específicas, não basta apenas apresentar atividades diferentes dos demais alunos. É preciso estimular os alunos com atividades que realmente sejam significativas para o educando e tragam melhorias em relação a aprendizagem dos alunos.

Então é preciso compreender o aluno com dislexia e apresentar uma intervenção acolhedora em sala de aula, para que esse aluno se desenvolva suas capacidades de leitura e escrita. Nesse contexto, é preciso que o professor esteja próximo ao aluno, que ele se sinta em sintonia no ambiente escolar e não apenas tratado com indiferença.

Dentro desse contexto Rodrigues (2018, p.20) assevera que:

Entendemos que o discente disléxico deve ser percebido na escola pelo olhar do acolhimento, ou seja, não deve figurar no contexto da sala de aula apenas numa perspectiva de integração, mas, sobretudode inclusão. As atividades no cotidiano da sala de aula devem corresponder às necessidades de aprendizagem destes sujeitos, muitas vezes, avaliados como incapazes, indisciplinados etc.

Portanto o aluno com dislexia precisa ter o apoio no ambiente escolar, encontrar atividades e metodologias que atendam suas necessidades de aprendizagens e isso somente é possível com professores preparados. Então existe uma necessidade que frente a problemas de aprendizagem os professores busquemidentificar quais são os fatores que levam esse 
aluno a não aprender.

\subsection{Avaliação de aprendizagem do aluno com dislexia}

O processo de avaliação sempre fez parte do ambiente escolar e da prática docente, constantemente ao longo da vida as pessoas são avaliadas, seja em um vestibular, prova de um concurso, entre tantos outros momentos. Mas o processo deavaliação vai além disso, ele faz parte da nossa vida, pois ao mesmo tempo que os indivíduos são avaliados também promovem a suas avaliações.

A avaliação fica evidente nas palavras de Lemos (2013, p. 54):

Desde criança, de uma maneira ou de outra, uma das primeiras coisas que aprendemos a fazer é observar. A partir da observação, admiramos o mundo à nossa volta e, à medida que vamos ganhandoexperiências, começamos a formular ideias, construir princípios e convicções que nos fazem tomar decisões e posicionamentos acerca dos inúmeros eventos com que diariamente nos deparamos ao longoda vida. Esses posicionamentos são regidos por julgamentos e ponderações, mesmo sem muitas vezes termos noção da palavraque define essas ações, a avaliação.

Logo, é possível observar que constantemente as pessoas usam a ferramentaavaliação para entender, controlar, e tomar decisões frente a situações que fazem parte do seu cotidiano. Esses processos avaliativos podem ter diferentes objetivos, no entanto são importantes para dimensionar a tomada de ações pelos sujeitos ou instituições.

Santos (2007, p. 2) complementa que:

O ato de avaliar implica na coleta, na análise e na síntese dos dados que configuram o objeto da avaliação, acrescido de uma atribuiçãode valor ou de qualidade, que se processa a partir da comparação daconfiguração do objeto avaliado com um determinado padrão de qualidade previamente estabelecido para aquele tipo de objeto.

A avaliação este presente na escola desde o princípio, é uma ferramenta usada para avaliar a aprendizagem dos alunos, inicialmente tinha apenas o papel demedir o aprendizado dos alunos e a promoção para séries seguintes. Lordêlo (2009) lembra que avaliação escolar era usado pelos professores como maneira de forçar os alunos a aprender ou se dedicar a decorar conteúdos com o objetivo de passar nas provas.

Segundo Weisz (2009) a avaliação escolar por muito tempo foi uma ferramenta autoritária do educador, pelo qual ele conseguia impor um certo tipo de medo nos alunos. Essa visão ainda é muito abordada inclusive na sociedade, constantemente as definições de 
provas são vistas como um momento de provação para o aluno.

"O sistema educacional, muitas vezes, tem se apoiado na avaliação classificatória com a pretensão de verificar aprendizagem ou competências através de medidas, de quantificações” (SANTOS, 2007, p.3). Esse tipo de avaliação que fezparte e ainda faz do sistema educacional recebe críticas de estudioso da educação, pois limita apenas a um método o modo de avaliar a aprendizagem dos alunos, definindo assim o sucesso ou fracasso do educando.

No entanto, o processo de avaliação educacional é uma ação ampla e que envolve vários fatores, como citado por Lemos (2013, p. 54):

No nosso entender, a avaliação como processo mediador e formativoda aprendizagem deve, necessariamente, caminhar ao lado do processo de ensino, subsidiando as etapas que compõem a aprendizagem. Acreditamos, também, que a avaliação da aprendizagem é um processo extremamente profundo que, inclusive, ultrapassa os muros da escola, sendo muito ampla para ser resumidaa uma única etapa e ao final do processo da aprendizagem, como fazem os testes e provas, por exemplo.

Como é possível compreender a avaliação não deve ser resumida apenas a aplicação

de provas no final de um período, que vai ocasionar em uma nota definitiva. Ela acontece em torno de um processo de ensino aprendizagem, e acompanha o aluno em toda a sua jornada dentro da escola, e oferece informações para o professor, a gestão escolar, a família e o próprio aluno.

Weisz (2009) afirma que a avaliação é um processo pedagogia que deve iniciar antes do aluno entrar em sala de aula, e deve se fazer presentes em todos os momentos educacionais. Ela tem a capacidade de dimensionar sucessos e fracassos, apresentando fatores que levam o aluno a ter dificuldades de aprendizagem, e também mostram ao educador correções que precisam ser feitasna sua própria atuação.

"Dentre as concepções de avaliação além da somativa e/ou classificatória, há também outras duas modalidades que são denominadas de avaliação formativa e a outra, de avaliação diagnóstica" (SANTOS, 2007, p. 3). Lemos (2013) define aavaliação formativa como sendo uma forma baseada na avaliação de aprendizagensdos alunos dentro de um determinado processo de ensino aprendizagem, com o objetivo de mostrar tanto para o professor como o aluno os fatores que precisam ser modificados para obter sucesso.

Weisz (2009) fala que a avaliação classificatória foi o tipo mais presente na educação brasileira, que tinha o objetivo de aprovar ou reprovar os alunos, e usada como ferramenta 
de autoritarismo pelos professores e sistemas. No entanto esse tipo de avaliação perdeu força nos últimos anos, com programas de aprovação automática em que os alunos não são mais reprovados.

Rodrigues (2018, p.2I) cita que:

O conhecimento por parte do educador sobre as dificuldades de aprendizagem específicas, dentre elas a dislexia é decisivo para que os alunos possam ter um desempenho melhor, a partir de um ensino adaptado às suas peculiaridades. É importante que a temática da dislexia seja reconhecida pelos governantes, para que, no âmbito das políticas inclusivas sejam promovidas formações continuadas para que os profissionais estejam preparados para identificar a dislexia e desenvolver ações educativas que os ajudem a prender e asuperar suas dificuldades

Atualmente muitos educadores tem defendido a avaliação diagnóstica, que pode ser usada em várias fases do processo de ensino aprendizagem, e através de diferentes ferramentas. "A avaliação diagnóstica é constituída por uma sondagem, projeção e retrospecção da situação de desenvolvimento do aluno, dando-lhe elementos para verificar o que aprendeu e como aprendeu" (SANTOS, 2007, p. 7).

O processo de avaliação ainda é classificado de acordo com duas maneiras, de maneira formal que é através de provas e testes previamente anunciados, e que geralmente atribuem uma nota ou conceito. E de maneira informal que acontece através da observação do educador em relação ao envolvimento do aluno ematividades, se consegue realizar e quais áreas tem mais dificuldades. (LEMOS, 2013).

Assim a avaliação no ambiente educacional se mostra como um processo complexo e que envolve diferentes fatores, mas que necessita ser usada para medir a aprendizagem do educando antes, durantes e após o processo educativo. Sempre com os objetivos claros e que proporcionem a abertura de novas possibilidades educacionais.

Santos (2007, p. 8) assevera que:

A necessidade de avaliar sempre se fará presente, não importando a norma ou padrão pela qual baseie-se o modelo educacional. Não há como fugir da necessidade de avaliação de conhecimentos, muito embora se possa, com efeito, torná-la eficaz naquilo a que se propõe: a melhora de todo o processo educativo.

Portanto, a avalição deve se fazer presente no ambiente educacional, independente se seja na escola, em uma empresa, no hospital, ou qualquer localque o pedagogo esteja inserido. A avaliação é uma ferramenta que faz parte da prática docente, e quando bem usada 
traz benefícios e melhorias no processo de ensino aprendizagem.

Em relação ao aluno com dislexia esse processo de avaliação deve sercuidadosamente elaborado pelo educador, pois ele deve considerar os limites do alunos e características próprias. Gernano (20II) afirma que uma avaliação de aprendizagem do aluno malconduzida pode ter consequências graves para o educando, pois atribui a ele um fracasso, relacionando com preguiça, ou outros problemas que o educando não tem.

Santos (2017) complementa que os resultados de problemas de aprendizagem do aluno com dislexia não devem ser atribuídos todos a esse distúrbio. O professor precisa ter um olhar atento, pois eles também podem teroutros motivos, nesse sentido é preciso que o educador conheça os limites e características do aluno com dislexia.

Portanto a avaliação do aluno com dislexia deve considerar todas as características desse educando, traçando um caminho que ele precisa alcançar, e o educador deve saber mediar essas expectativas para que seja alcançada. Assim o processo de avaliação é uma ferramenta necessária dentro do processo de ensino aprendizagem, para se consiga elaborar parâmetros e metas a serem atingidas de acordo com as possibilidades de cada aluno.

\section{CONCLUSÃO}

Após a realização desse trabalho de pesquisa sobre a dislexia é possível concluir que esse distúrbio é ainda pouco conhecido no meio escolar, até poucos anos atrás poucos professores tinham conhecimento sobre esse transtorno. E hoje ainda em sala de aula tem professores que rejeitam a dislexia, apontando outros fatores para dificuldades de aprendizagem como problemas familiares e falta de vontade dos alunos.

Porém esse estudo revelou que aproximadamente $5 \%$ dos educandos tem dislexia, logo todo professor em sua trajetória docente vai encontrar alunos comesse distúrbio de aprendizagem. Portanto não é aceitável que se feche os olhos para essa dificuldade de aprendizagem, o educador precisa ser atento e ativo frente a qualquer dificuldade encontrada pelo aluno em sala de aula.

O procedimento investigativo é ponto de partida na busca de respostas frente aos problemas de aprendizagem, e conhecer as características de crianças disléxicas é fundamental para que esse distúrbio não passe despercebido peloeducador. Então o educador precisa conhecer a dislexia para que consiga identificar esse distúrbio e realizar o 
encaminhamento para os profissionais especialistas paraa montagem de planos de ação para intervir no problema.

Além disso o educador deve acompanhar o aluno em sala de aula, com atividades especificas para desenvolver a habilidade de leitura e escrita do aluno com dislexia. No entanto, deve haver um cuidado para que não aconteça uma separação e exclusão desse aluno em sala de aula, pois isso prejudica ainda mais o aluno.

A atuação do educador deve ser baseada em um olhar atento para as características do aluno, evidenciando e elaborando estratégias frente as necessidades de aprendizagem. $\mathrm{O}$ educador precisa motivar o aluno para que busque a aprendizagem, seja através da escrita, oralidade, pensamento, no sentido de desenvolvimento e ultrapassando os limites de acordo com as características especificas.

Para finalizar esse trabalho trouxe aprendizagens em relação a dislexia, revelou a necessidade de o educador estar atento em sala de aula para identificar esse distúrbio, e seu papel é fundamental no sucesso do aluno disléxico dentro do futuro escolar e depois na sua vida fora da escola. Assim essa pesquisa se mostrou produtiva, e reforça o fato que o educador precisa sempre buscar novos aprendizados em relação não apenas ao ensino, mas sim na aprendizagem do aluno.

\section{REFERÊNCIAS BIBLIOGRÁFICAS}

ABD. Associação Brasileira de Dislexia. Disponível em: http://www.dislexia.org.br/. Acesso em: 12/o9/2019.

ALMEIDA, Gisela Souza dos Santos. Dislexia: o grande desafio em sala deaula.Revista Eletrônica de Divulgação Científica da Faculdade Don Domênico - $2^{\underline{a}}$ Edição - Outubro de 2009

ALVES, Cleto de Assis. A Dislexia e suas implicações no contexto escolar: umaquestão emergente para os educadores. Disponível em: http://www.diaadiaeducacao.pr.gov. busca/producoes_pd e/2014/2014_uepg_gestao_artigo_cleto_de_assis_alves.pdf Acesso em 24/o9/2019.

BARROS, Célia Silva Guimarães. Pontos de Psicologia Escolar. Editora Ática S.A.2007.

FONSECA, J. J. S. Metodologia da pesquisa científica. Fortaleza: UEC, 2002. Apostila.

GERMANO, Donadon Germano. Desempenho de escolares com dislexia, transtornos e dificuldades de aprendizagem em provas de habilidades metafonológicas (PROHFON). J Soc Bras Fonoaudiol. 20II. 
GIL, Antonio Carlos. Como elaborar projetos de pesquisa. 5. ed. São Paulo: Atlas,2010. I84p

LADEIRA, Marileide da Silva. Educador: A dislexia e o que fazer em sala de aula? XIII Encontro Latino Americano de Iniciação Científica eIX Encontro LatinoAmericano de PósGraduação - Universidade do Vale do Paraíba. 2009.

MASSI, Giselle. A dislexia em questão. Editora Plexus. 2006.

MEDEIROS, Maria Celina Gazola. O que os professores conhecem sobre dislexia e o transtorno de déficit de atenção. São Paulo: SESI-SP editora, 2012.124 p.

MOJEN, Sônia. Características da dislexia de desenvolvimento e sua manifestação na idade adulta. Rev. Psicopedagogia 2016

MUSZKAT, Mauro. O professor e a dislexia. - São Paulo: Cortez, 2017.

LIMA, Iris Giane Soares. A dislexia e o contexto escolar. Anhanguera • Vol. V, №.N, Ano $2012 \cdot$ p. I-I5.

PRESTES, Marta. Teorias da Dislexia: Sustentação com Base nas Alterações Perceptuais Auditivas. Psicologia: Teoria e Pesquisa.

RODRIGUES, Sônia das Dores. Dislexia na escola: identificação e possibilidades de intervenção. Rev. Psicopedagogia 2016; 33(I00): 86-97

RAMOS, Daniela Karine. Jogos Digitais na Escola: aprimorando a atenção e a flexibilidade cognitiva. Educação \& Realidade, Porto Alegre, v. 43, n. 2, p. 531-550, abr./jun. 2018.

RODRIGUES, Yanna. Dislexia e prática docente: reflexões sobre as experiências e intervenções pedagógicas de professoras no contexto do município de Guarabira/pb.

Disponível em:

http://www.editorarealize.com.br/revistas/eniduepb/trabalhos/TRABALHO_EVo43_M

Di_SAI4_IDI450_o1072015152949.pdf

Acesso em 20/09/2019.

TARDIF, M. Saberes docentes e formação profissional. RJ: Vozes, 2002.

SANTANA, Alexandre. A história do lúdico na educação. REVEMAT, eISSN 1981-1322, Florianópolis (SC), v. o6, n. 2, p. 19-36, 2011.

SANTOS, Monalize Rigon dos. A avaliação como um instrumento diagnóstico da construção do conhecimento nas séries iniciais do ensino fundamental. Revista Eletrônica de Educação. Ano I, No. oI, ago. / dez. 2007

SALVARI, Lúcia de Fátima Carvalho. Os problemas de aprendizagem e o papelda família: uma análise a partir da clínica. Estudos de Psicologia I Campinas I 23(3) I 251-259 I julho - setembro 2006 
TEIXEIRA, Amandio. Antes que eles acabem com o Brasil. Campinas: Papirus. 2015.

WEISZ, Telma. O diálogo entre o ensino e a aprendizagem. São Paulo: Ática, 2009. 